\title{
Alleviation of saline water stress on tomato (Lycopersicon esculentum Mill.) plants by irrigation scheduling and foliar application of salicylic acid and potassium sulphate
}

RAMANDEEP KAUR, I. J. GULATI, DINESH KUMAR AND PRAMENDRASINGH

Received : 18.01.2017; Revised : 08.04.2017; Accepted : 21.04.2017

MEMBERS OF RESEARCH FORUM:

Corresponding author : DINESH KUMAR,Department of soil Science and Agricultural Chemistry, College of Agriculture, S.K. Rajasthan Agricultural University, BIKANER (RAJASTHAN) INDIA

Email: dkrachiata@gmail.com

Co-authors :

RAMANDEEP KAUR, I. J. GULATI AND PRAMENDRA SINGH, Department of soil Science and Agricultural Chemistry, College of Agriculture, S.K. Rajasthan Agricultural University, BIKANER (RAJASTHAN) INDIA

\section{Summary}

One of the main hurdles in boosting the agricultural production in arid and semi arid areas of world is the scarcity of good quality water for irrigation. The quality of irrigation water plays a key role in judging its suitability for crop production. Soil and water salinity is an abiotic stress and limiting factor which affects almost every aspect of physiology and biochemistry of a plant, resulting in reduction in its yield. The research entitled alleviation of saline water stress on tomato (Lycopersicon esculentum Mill.) plants by irrigation scheduling and foliar application of salicylic acid and potassium sulphate. was conducted at Niche area of excellence, S.K. Rajasthan Agricultural University, Bikaner during Rabi season of 2015-16. The result shown that biochemical parameters APX, SOD, POX and CAT activity significantly increased with the increase in irrigation interval from daily irrigation to third day irrigation. The effect of irrigation levels on APX, SOD, POX and CAT activity significantly increased from 1.0 vol. (full volume of water required by crop) to $0.8 \mathrm{vol}$. ( $80 \%$ of full volume of water required by crop) and at par to 0.6 vol. ( $60 \%$ of full volume of water required by crop). The application of salicylic acid and potassium sulphate resulted in significant increase in APX, SOD, POX and CAT activity over control at application of $500 \mathrm{ppm}$ and $15 \mathrm{~m} \mathrm{~mol}$, respectively. The physiological parameters viz., electrolyte leakage and relative leaf water content (RLWC) decreased with the decreasing irrigation levels from 1.0 vol. to $0.8 \mathrm{vol}$. and at par to $0.6 \mathrm{vol}$. The electrolyte leakage and RLWC decreased with the increase in irrigation interval from daily to third day irrigation. With the application of salicylic acid and potassium sulphate the physiological parameters increased significantly. The quality parameters also fluctuate with the treatments. The TSS and ascorbic acid content of tomato decreased with the increase in irrigation levels as well as irrigation intervals and increased with the application of salicylic acid and potassium sulphate. The similar results were found with the yield and yield attributes, the number of fruits per plant, avg. diameter of fruit, avg. weight of fruit and yield of fruits decreased with the increase in the irrigation interval and irrigation levels and increased with the application of salicylic acid and potassium sulphate. The soil was non-significantly affected with all the treatments of research.

Key words : Saline water stress, Irrigation scheduling, Salicylic acid, Potassium sulphate 